\title{
The Role of Publication in Promoting University Reputation: A Case Study IAIN Bukittinggi
}

\author{
Gusti Milla Quaidy ${ }^{1}$, Meilanie Zohra ${ }^{2}$, Melyann Melani ${ }^{3}$, Alfu Syahri ${ }^{4}$, Veni Roza ${ }^{5}$ \\ \{GustiMillaQuaidy@gmail.com ${ }^{1}$, Meilaniezohra14@gmail.com², \\ melyannmelani@gmail.com ${ }^{3}$, alfusyahri56@gmail.com ${ }^{4}$, veniroz_501@yahoo.com ${ }^{5}$ \} \\ English Education Study Program, Institut Agama Islam Negeri (IAIN) Bukittinggi, Indonesia ${ }^{1,2,3,4,5}$
}

\begin{abstract}
This research identified the role of scientific publication in higher education level in which it has highly contribution on promoting university scientific reputation. It occurs because there are particular obstacles that happen with lecturers to conduct the research, therefore it creates the unproductive publication upon universities in which most of researchers from universities realized that it will not only give impact on universities but it will also impact on lecturers research activity performance. Thus, this study will investigate the role of scientific publication on promoting university reputation.
\end{abstract}

Keywords. scientific publication, lecturers, university reputation

\section{Introduction}

University is a higher education institution where it gives many contributions on sustainable society enhancement. Recently, almost all of universities compete and provide considerable financial toward research development to get the reputation and high score in accreditation. It occurs because accreditation is one of the influenced parts in getting the society belief where most of society paradigm that accreditation describes the quality of university. Society believes that university which has good accreditation has good performance in all aspects whether it is in lecturers' quality, facilities, students' satisfaction, and etc. In case, university which has worthy accreditation will impact to all of field study including English education section at IAIN Bukittinggi. It occurs because a university with the good accreditation. Thus, accreditation is necessary to decide the society choice for higher education. Reaching the goal in getting high score in accreditation is required all of stakeholders in each universities work hard implement the goal through number of aspects that can indicate qualified university because those aspects will impact on university accreditation. One of the aspects is lecturers' Publication. Publication is one of essential component in university. It occurs because it can increase the university's reputation. Czellar stated "Universities are required to increase the visibility of their scientific activities."[1] It means that universities are supposed to increase their scientific publication frequency where all of lecturers should be active in writing the scientific journal. The publication activity can indicate the lecturers' productivity in creating scientific writing. In result, it shows the public that the university has potential researcher.

Publication is not only essential component in increasing university reputation but it is also one of three points of Indonesia' principle in higher education. There are three points in 
Indonesia's principle of higher education, they are; Teaching, Research and Community service. Based on three points of Indonesia's principle in higher education, publication is considered as the research field.

There are two kinds of publications which are commonly known based on the separation which is given by zhang, they are journal publication and conference proceeding. Journal publication is commonly expected to present the paper through presentation in conference, whereas journal publication is required the authors to send their paper through the journal web.[2] Increasing the quality of the university, the lecturers are required to publish their publication through the accredited, international or international reputation journal and national or international proceeding. Educational institution should have full documentation and evidence on research as seen in the number, scope and impact of scholarly publications in refereed national and international journals.

IAIN Bukittinggi is one of Indonesian Islamic universities which obligate the lecturers to publish their scientific publication. The lecturers who actively publish their scientific writing can indicate the lecturers have worthy potency in writing because writing is not an easy activity in which lecturers need to have time and to read more books. All of the lecturers are required to publish their scientific writing including the entire lecturers in English education section of IAIN Bukittinggi into national, international, accredited and Scopus indexed journal databases for their career requirement and for university reputation enhancement. All of lecturers realized the function of scientific publication in university but there are still number lecturers who are lack of productivity in scientific publication activity. Here are some factors which impact on lecturers' low productivity in publication activity in university; they are English language mastery, lack of motivation, lack of Reading and writing habit, and so on. Factually, Based on survey in online publication databases and interview with LP2M at IAIN Bukittinggi, the researcher found several problems. First problem is the lecturers' publication activity is still low. Based on three points of Indonesia principle of higher education that the lecturers in higher education are required to fulfill three items, they are; teaching, research and community service. All of the lecturers have highly contributed in teaching activity in the classroom. Additionally, the university also provides the students to join internship where the students are required to interact with the society. However, the last point cannot be fulfilled by the lecturers at IAIN Bukittinggi. It is proven by the interview which was done by the researcher with LP2M at IAIN Bukittinggi where all of lecturers were required to do research and to write the research, unfortunately only few of them were able to publish their scientific research.

\section{Scienthic Publication}

\subsection{Definition of Scientific Publication}

In education 4.0, university reputation is really fundamental in interesting society to take attention at the university. According to Bergerson in Hazelkorn that Students consider a range of issues when making choosing a college and university; this includes, for example, price and cost, course or program, location, quality of facilities, social life and academic reputation.[3] There are several factors that can enhance the university quality; one of them is lecturers' Scientific Publication. University needs to occupy the lecturers to fulfill three points of Indonesia's principles of higher education (Tri Dharma Perguruan Tinggi); they are education, research and community service. Those points have crucial impact on university performance. 
First, education is one of the obligations of lecturers in higher education because it is the main function of higher education to educate. After that, research is an activity of lecturers in higher education toward university reputation and lecturers' academic promotion. The last is community service. It is an activity where stakeholder of university needs to conduct a contribution on society. From those points in Indonesia's principles of higher education, research is the focus on this research because it gives the contribution of lecturers' academic promotion increasingly. It means that lecturers who actively publish their scientific writing will be given reward, in this case lecturers' academic promotion so that it is one of the factors in lecturers' prosperity development and in university reputation development. Thus, scientific research is the main focus in this research.

Scientific Publication or Academic Journal is therefore, the 'chat room' for the exchange knowledge, new theorizations or interesting syntheses or re-presentations of existing knowledge.[4] It defines that scientific publication or academic journal is used to express an idea toward current issue in the lecturers' field study. It is usually done by the lecturers at university to fulfill their need in increasing their academic level in a university. From the explanation can be concluded that being researcher needs to focus on publishing the scientific publication or academic journal. It occurs because purpose of writing academic journal is for publication activity. The Differences among Journal and Proceeding Publication Conference Proceeding and Journal Publication are scientific activity where they are involved researchers to do research to look for the current issue of several research background, such as economic, politic, social, education, and etc. Even though they have similarity as scientific activity, both of them still have difference in several aspects, they are; step before publishing and selecting step.

\subsection{The Phases in Conference Proceeding and Journal Publication}

\subsubsection{Pre-Publishing}

Conference proceeding has difference in publishing the writing product. It needs to join conference which is conducted by several institutions, such as university, government institution, organization, and etc. Zhang and Glanzel mentioned that Conference Proceeding mainly focus on the innovation and proposal of new ideas,[2] whereas journal publication can more strongly contribute to build a knowledge base. In addition, Conference Proceeding mostly focuses on innovation research based on the current situation which is suitable to be applied. The purpose of doing presentation before publishing the finding of the research is to promote the innovation and research which is found by the researcher. In fact, the audience and the reader will know the newest findings of that innovation. On the other hand, the journal publication is only proceeded to the journal web. For example, the authors or researchers are supposed to submit their research to the link journal, such as TEFLIN, ELITE, Asian Journal, and etc. The researchers do not need to present those researches because the research will be selected by the reviewers.

\subsubsection{Publishing}

The difference of conference proceeding and journal publication is not only from prepublishing but it also comes from the publishing. Publishing means that the writing that has been written will be published in some publication databases. In conference proceeding, the academic journal will be submitted to the committee and the selected abstract is supposed to be presented in conference. Additionally, the paper which has been presented in conference will be published in proceeding either it is in international proceeding or it is in national 
proceeding. Meanwhile, journal publication is more complete where the researcher is only supposed to submit the journal to the link journal, such as TEFLIN, ELITE, Asian Journal, institutional journal, and etc. Those journals will be selected by the reviewers. Conferences permit researchers to present initial study, collect feedback from colleagues and advance next study, while journal papers are usually more complete, correspond to a more mature report of the study and have some archival purpose. The expert statement shows that Journal publication is more difficult because it is supposed to be selected well by the reviewer. It happens because there will be more researchers who will send their studies to the journal publication to be selected. In order, the journal publication will be accredited so that all of the studies will be considered well, while the proceeding is not needed to be accredited. It is only divided into national or international proceeding.

\subsubsection{Databases for Publication}

Databases are used to use by researcher to publish their journals. According to Naqvi that A large, regularly updated file of digitized information (bibliographic records, abstracts, fulltext documents, directory entries, images, statistics, etc.) related to a specific subject or field, consisting of records of uniform format organized for ease and speed of search and retrieval and managed with the aid of database management system (DBMS) software. Naqvi has clearly defined how the databases work in publishing any kinds of information (included Academic Journal). Researcher can use the online databases by registering themselves into the database. In other case, the researcher is also able to submit their paper to be published by institutions. The part of Electronic Databases mostly is known as Google Scholar, Scopus, SINTA, and etc. Those databases are commonly used by the researchers to publish their academic journal by presenting those journals to the conference or by publishing those journals to journal publication (e.g. TEFLIN, ELITE, Institution Journal, and etc). Those journal publications are commonly integrated to the Databases. One of the example is TEFLIN is connected to Google Scholar and the researcher can access the journal in Google Scholar by typing the title of journal or the authors' name.

\subsubsection{Sample of Journal and Proceeding Publication}

SINTA and Google Scholar are publication databases in which all of lecturers' publication will be registered in the database. In case, SINTA only recognize the publications which published in reputational databases whether they are national accredited journal, indexed scopus proceeding and journal and international journal. It is necessary to lecturers to publish their work to valuable journal. according to Bavdekar and Save "It is often considered the valuable of one's research work can be blamed better by the names of journals where the writing is published rather than by the titles of the journals that have been written." It strengthens that lecturers should consider journals that they intend to publish. It should be considered based on its indexed, visibility and prestigious.

\section{Measurement Of Lecturers' Productivity In Research Field}

Measuring research productivity is significant part in university. It occurs because it is an evaluation of the stakeholder in university to find solution if there are obstacles that are found in university. The study ranked the most desirable indicators in the following order: quality of publication, honors and awards, peer review, and influence on other research. It strengthens that 
quality of journal databases which are used by the lecturers to publish their scientific publication is one of the indicators of lecturers productivity and also following other factors in which is citation rate of each publication of the lecturers.

\section{The Role Of Scientific Publication}

Nowadays, Scientific Publication is used to employment need in a university. It happens because the lecturers at university can increase their academic level. Academic level impacts teacher's salary number and it also impacts the position of the lecturers. For example, the lecturers who are used to publish their academic journal will be earlier to get level promotion in that university. In case, it can make lecturers who have the high level will have an opportunity to be the head of field, dean of faculty, and etc. Scientific Publication is not only needed for the lecturers but it is also needed to increase the university publication ranking. Usher and Savino in kehm and stensaker strengthen that study first, by making clearer distinction between financial resources and staff and second by including two others sets of indicators, namely 'research' and 'reputation'.[5] It clarifies that research also one of the aspects that will give its involvement in university ranking. It occurs because the researcher of university needs to do long term before conducting a research. They need to understand the current issues related the background of researcher field study and they also need to do preliminary research to know the main problem in the case.

Furthermore, Scientific Publication or Academic Journal does not only concentrate at focusing on publishing the writing product, but the writer or researcher also needs to focus on the reputation of the journal (platform). The lecturers are supposed to consider the journals that they aim to publish in which lecturers are require to publish their articles to indexed journals, higher visibility, and prestigious.. It is because the qualified scientific publication is a publication which is published in accredited or reputable journal whether it is National Journal or International Journal and national proceeding or international proceeding. In case, the score of accredited or reputable publication is higher than the unaccredited publication, thus, it can give more impact in university reputation.

Additionally, scientific publication is not only published in journal web, it also can be published in conference proceeding. The lecturers or researchers need to join conference to present their paper to responsible the research product. Based on Albo and Bordons research that conference has necessary role in scholarly discussion, since it offers scientists with a chance to present and converse prior result of their research and increase their personal social networks.[6] In order, joining conference to present the paper is one of opportunities to enlarge social networking in linear background. The explanation above defines that conference proceeding is also crucial part in university circle. It occurs because it is also part of scientific activity where all of lecturers at university mostly will contribute in participating in that conference. In short, scientific publication serves the some functions such as, increasing lecturers' academic level, enhancing university reputation, enlarging the social networking in linear background.Authors and Affiliations. 


\section{Conclusion}

This study clearly defines that the contribution of scientific publication on university scientific reputation in which the university reputation will highly give impact on students' learning outcome, lecturers' promoting academic level, and also university accreditation. Therefore, university stakeholders are required to take control the publication performance of the lecturers upon the universities. It occurs because the publication also will contribute to promote the lecturers with the students in which the students will be familiar with their lecturers study point of view.

\section{References}

[1] J. Czellar and J. Lanarès, "Quality of research: Which underlying values?," Scientometrics, vol. 95, no. 3, pp. $1003-1021,2013$.

[2] L. Zhang and W. Glänzel, "Proceeding papers in journals versus the ' regular' journal publications," J. Informetr., vol. 6, no. 1, pp. 88-96, 2012.

[3] E. Hazelkorn, "The Effects of Rankings on Student Choices and Institutional Selection," vol. 2012, 2014

[4] D. Epstein, J. Kenway, and R. Boden, "Writing for Publication. The academic's support kit," 2005.

[5] B. M. K. and B. Stensaker, Diversity, and the New Landscape of. .

[6] B. González-Albo and M. Bordons, "Articles vs. proceedings papers: Do they differ in research relevance and impact? A case study in the Library and Information Science field," J. Informetr., vol. 5, no. 3, pp. 369-381, 2011. 